\title{
Editorial
}

\section{Spectroscopy and proteomics}

In my first editorial in Spectroscopy, I stressed that the future of spectroscopy, in the post-genomic era is a bright one, and that it will play a pivotal role in the field of proteomics [1]. Indeed, the 2002 Nobel Prize in Chemistry goes to three researchers who helped develop two of the key spectroscopic techniques in this field, namely NMR and mass spectrometry. Half of the prize was awarded to Kurt Wüthrich of the Swiss Federal Institute of Technology in Zürich and the Scripps Research Institute in La Jolla, California, for his pioneering role in developing NMR spectroscopy for elucidating the three-dimensional structures of large biomolecules such as proteins in solution. John Fenn and Kiochi Tanaka from Virginia Commonwealth University in Richmond, and Shimadzu Corporation in Kyoto, respectively share the other half of the prize for their role in developing mass spectrometry for characterisation of large protein molecules.

Proteomics was also a major theme in the First International Conference on Biomedical Spectroscopy, which was held in Cardiff, Europe's youngest capital city, between 7-10 July 2002. The conference brought together scientists, with background in basic and clinical science, sharing in common, the application of spectroscopy for the analysis of diverse systems ranging from small biomolecules to human beings. Leading experts, and young scientists, from over 30 countries on six continents took part in this conference which was opened by Rhodri Morgan MP AM, the First Minister of the Welsh Assembly. Erwann Loret, Charge De Recherche in the Centre National De la Recherche Scientifique, Institut de Biologie Structurale et Microbiologie, Marseille, France delivered the opening scientific lecture of the conference. Loret has the distinction of being the first European to be awarded the GlaxoSmithKline Drug Discovery and Development Award in 2001 for his work in designing molecules to inhibit the spread of Aids. Loret described how NMR spectroscopy is a powerful tool in developing novel drugs to combat HIV.

The particular feature of the conference was the rich diversity of topics and techniques covered. The interdisciplinary nature of the conference provided an excellent opportunity for scientific interchange and cross-fertilisation of ideas. Basic scientists and clinicians presented their work, describing how different spectroscopic techniques can not only provide insights into the molecular properties of biomolecules, but how they can be used as diagnostic tools for detection of life-threatening disease states such as cancer.

The first international conference was dedicated to the memory of Dennis Chapman FRS. Chapman was a great believer in the application of spectroscopy for analysis of complex biological molecules. He was a pioneer in the application of several techniques for biological studies including NMR and infrared spectroscopy [2]. In his final years, Dennis Chapman was working hard to extend the application of FTIR spectroscopy for obtaining detailed information on protein structure. It is therefore fitting that Yukihiro Ozaki from the Kwansei-Gakuin University, Japan presented the first Chapman Lecture, dedicated to the memory of Dennis Chapman. Ozaki, spent the first part of the lecture highlighting some of the notable achievements of Dennis Chapman which made him a truly great biospectroscopist. He then went on to describe his own pioneering work on the development of two-dimensional FTIR spectroscopy for protein structure analysis. 


\section{References}

[1] P. I. Haris, Editorial: Spectroscopy in the post-genomic era, Spectroscopy 15 (2001), 45-46.

[2] P. I. Haris, Dennis Chapman (1927-1999) - Obituary, Trends in Biochem. Sci. 25 (2000), 104-105.

Parvez I. Haris Editor-in-Chief Spectroscopy - An International Journal E-mail: pharis@dmu.ac.uk 


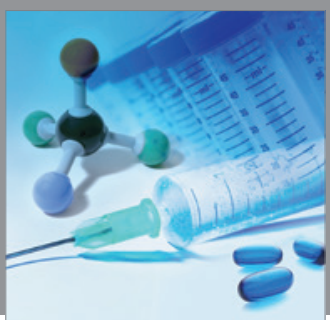

International Journal of

Medicinal Chemistry

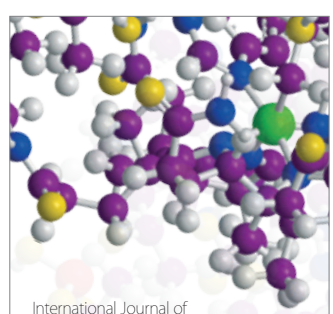

Carbohydrate Chemistry

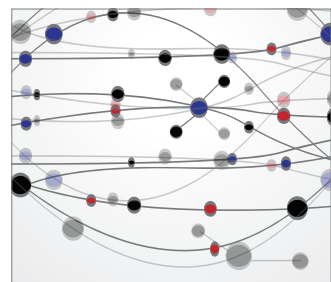

The Scientific World Journal
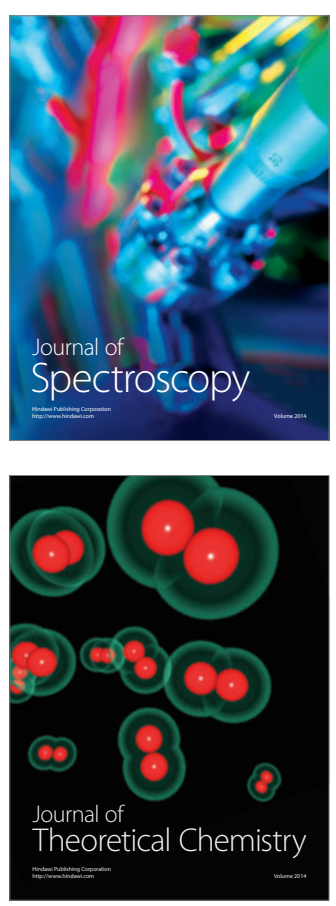
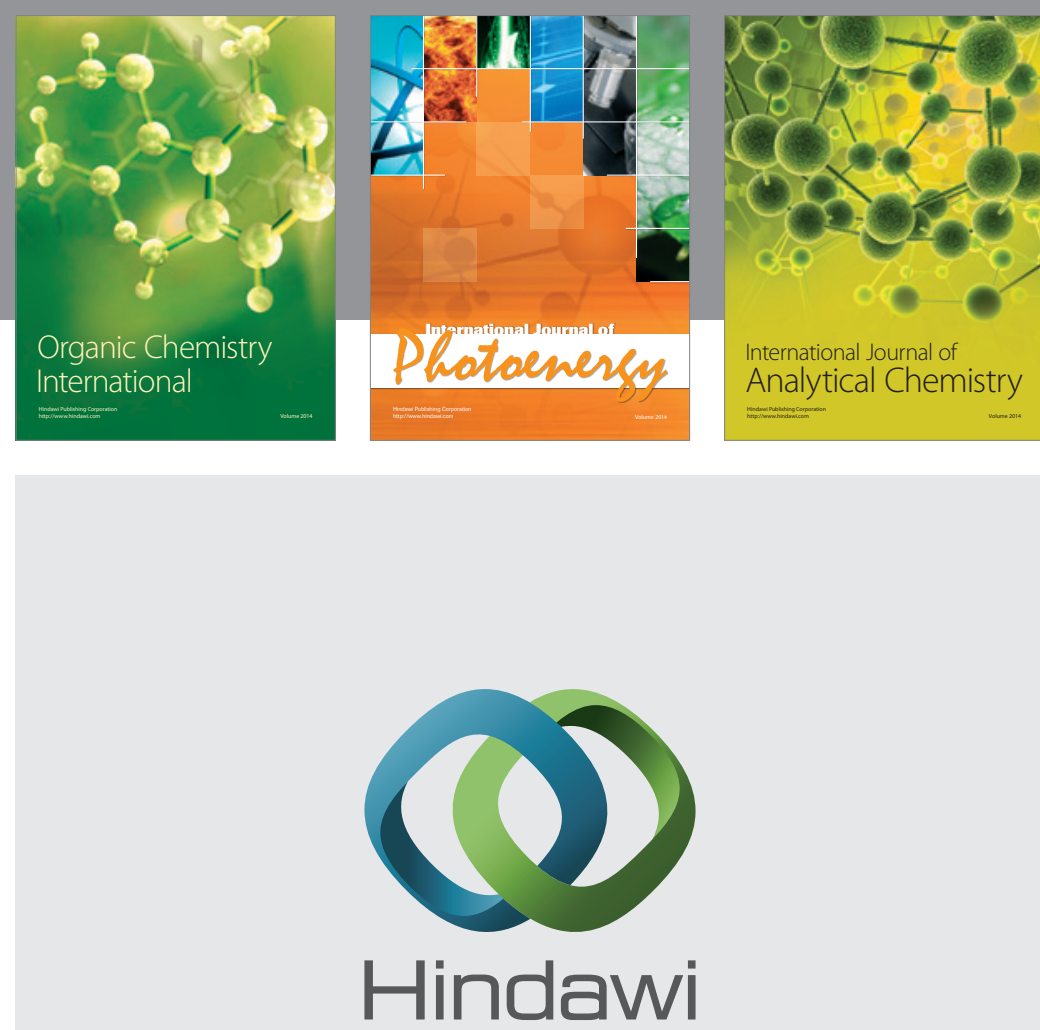

Submit your manuscripts at

http://www.hindawi.com
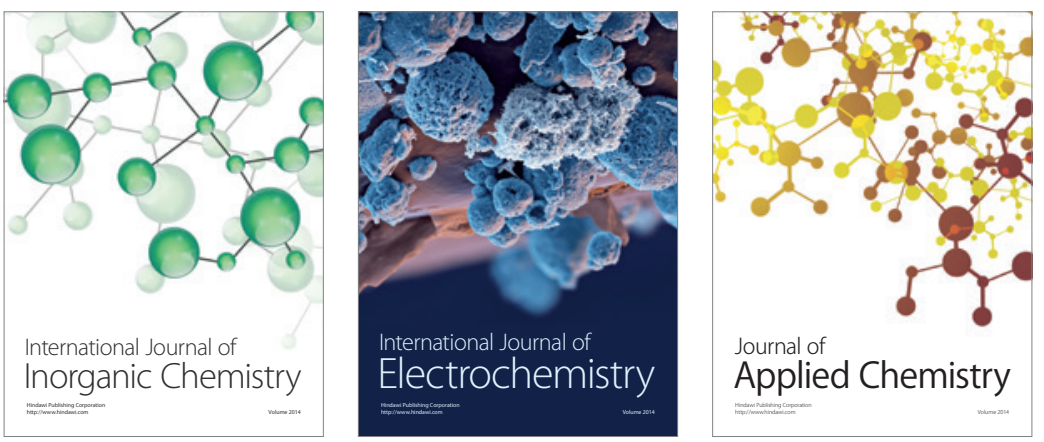

Journal of

Applied Chemistry
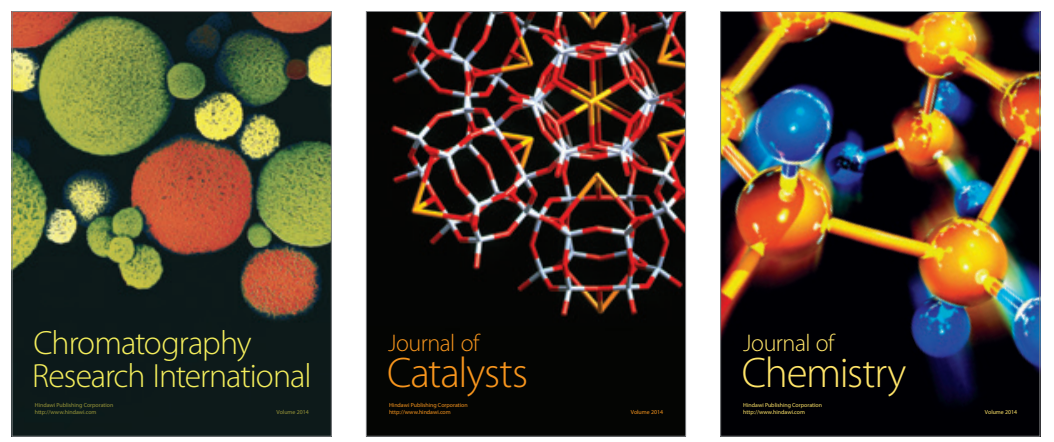
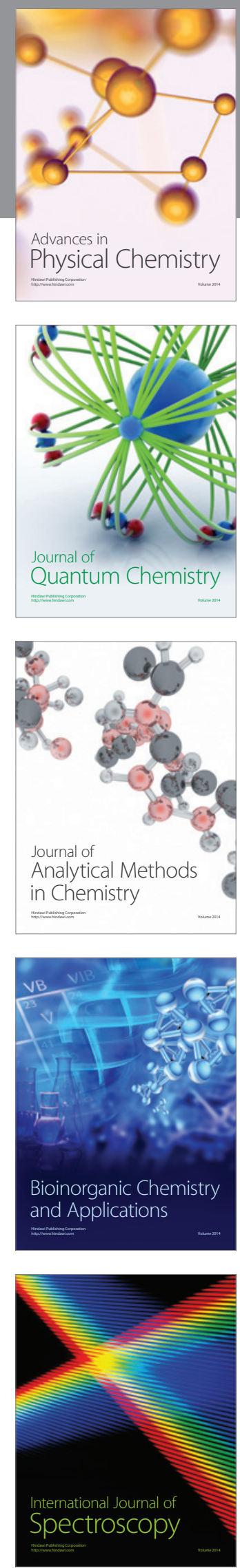